\title{
Computer controlled detonation spraying: a spraying process upgraded to advanced applications
}

\author{
I. Smurov ${ }^{1} \&$ V. Ulianitsky ${ }^{2}$ \\ ${ }^{I}$ Ecole Nationale d'Ingénieurs de Saint-Etienne (ENISE), \\ DIPI Laboratory, France \\ ${ }^{2}$ Lavrentyev Institute of Hydrodynamics SB RAS (LIH SB RAS), Russia
}

\begin{abstract}
In the present work Computer Controlled Detonation Spraying (CCDS) developed in recent years is described, and the coating formation is studied based on the analysis of: (a) particle acceleration and heating in a gun barrel; (b) particle collision with the substrate and the bond formation; (c) analysis of the coatings composition and microstructure. One of the CCDS' peculiarities is a pulsed lateral injection of the powder into the barrel at a chosen point. The developed mathematical model permits us to find the particle velocity and temperature as a function of the detonating gaseous mixture composition, the volume of this mixture (barrel filling), the location of the powder injection into the barrel. Theoretical results were verified experimentally using CCD-camerabased diagnostics.

CCDS coatings can be deposited on substrates made of metals, ceramics, plastics, even wood and can coat surfaces of complex shapes with an incidence angle up to 45 degrees. For the majority of materials the coating thickness can exceed several millimeters. CCDS gives extended possibilities for deposition of composite and graded coatings using twin powder feeders. Computer control provides real-time adjustment of the spraying conditions for two different powders. Several model composite and multi-layered coatings, including metalmetal, metal-cermet, cermet-ceramic, ceramic-ceramic were deposited and analyzed.
\end{abstract}

Keywords: detonation spraying, protective coatings, fuels for spraying, composites, cermets, multicomponent coating, powder injection, optical diagnostic, splats, particle-in-flight. 


\section{Introduction}

Detonation spraying (DS) is one of the thermal spraying technologies which are widely used for the deposition of wear resistant, electro-insulating, surface protecting, and other functional coatings on surfaces and mechanical parts from different materials. A comprehensive description of the gas detonation phenomenon and a review of its technological applications are given in [1]. DS was firstly employed in 1950s in USA [2, 3], and in 1960s in the former USSR [4].

A new-generation DS system equipped with computer control was recently realized in Lavrentyev Institute of Hydrodynamics Siberian Brunch of Russian Academy of Science (LIH SB RUS) [5], and one set of such equipment with a computer-controlled manipulator was installed in National Engineering School in St-Etienne, France (ENISE) in 2007. The actual Computer Controlled Detonation Spraying (CCDS) device CCDS2000 is characterized by a computer control system, robot compatible spraying unit, a portable chiller, two powder feeders, etc.

Detonation spraying strongly relies on the precision of the operating settings such as composition of the explosion mixture, charge volume, method and location of the powder injection and on the tight control of the process parameters without which optimal spraying conditions for the chosen powder cannot be ensured. In CCDS2000, the numerically controlled gas supply system and the twin powder feeding system are supported by special software that permits to control the explosion charge formation inside the barrel by varying the consumption of the two fuels, the oxidizer and the inert gas, and conditions of the powder injection. Computer control provides a flexible programmed readjustment of spraying parameters for each single shot as well as their frequency. During spraying, the computer is checking all executors and safety blockings of the auxiliary equipment. Computer-controlled relative motion of the detonation barrel and the substrate allows us to apply different deposition strategies adjusted for different part geometries.

CCDS technology is currently under intensive development by joint efforts of LIH SB RAS (Novosibirsk, Russia) and DIPI laboratory of ENISE (Saint Etienne, France).

\section{Detonation spraying simulation}

DS is characterized by a set of parameters including the detonating gaseous mixture composition, the volume of this mixture (barrel filling), the location of the powder injection into the barrel, etc. DS process was theoretically described by the following ways: First, the detonation parameters for a given fuel-oxidizer gaseous mixture were calculated; then, the particle velocity and temperature $(V \& T)$ were found using the solution obtained at the first step. The calculation procedure for the particle $V \& T$ is thoroughly described in [6]. On this basis, original software was developed: It calculates parameters of the detonation products of any gaseous hydrocarbon fuels and hydrogen. 
Different combustible gases can be used in DS. For the gas fuel-oxygen mixtures, detonation can be initiated in a wide range of fuel-oxidizer ratios. However, only a narrow range of these ratios is suitable for initiating a detonation by such a simple device as the car ignition system which is generally used in the detonation spraying installations.

Other important parameters of the detonation mixture are temperature $\left(T_{I}\right)$, density $\left(\rho_{l}\right)$, detonation front velocity $(D)$ and mass velocity $\left(u_{l}\right)$ of the detonation products (DP) which denote the maximum values of these parameters during particle heating and acceleration.

DP chemical composition is also of importance. In a general form, the chemical reaction equation for any hydrocarbon fuel and hydrogen shows that DP can contain even such strong oxidants as atomic oxygen:

$$
\begin{aligned}
& \Sigma \mathrm{Cn}_{i} \mathrm{Hm}_{i}+b_{3}^{c} \mathrm{O}_{2}+b_{4}^{c} \mathrm{H}_{2} \leftarrow{ }_{\rightarrow} b_{1} \mathrm{CO}_{2}+b_{2} \mathrm{H}_{2} \mathrm{O}+b_{3} \mathrm{O}_{2}+b_{4} \mathrm{H}_{2}+b_{5} \mathrm{OH}+b_{7} \mathrm{CO} \\
& +b_{8} \mathrm{O}+b_{9} \mathrm{H},
\end{aligned}
$$

where $\mathrm{Cn}_{i} H m_{i}$ is a general expression of hydrocarbon fuel in which $n_{i}$ and $m_{i}$ have values from 1 up to 10 for gaseous fuels (for example, at $n_{i}=4$ and $m_{i}=10$, butane fuel is written as $\left.C_{4} H_{10}\right) ; b_{i}^{c}$ and $b_{i}$ are stoichiometric coefficients in the chemical reaction equation for the initial and final products, respectively.

Comparative analysis of the fuels led to the following conclusions: Hydrogen is a too weak explosive for the detonation spraying because of a relatively low density of its detonation products and, correspondingly, small kinetic head. Methane yields the minimal kinetic head and has the lowest blast sensitivity among the tested hydrocarbons and, therefore, also is not a good choice for detonation spraying. DP parameters of ethane, propane, butane, and propylene stoichiometric compositions with oxygen do not differ much. In the fuel-rich compositions, butane slightly excels over the whole range of hydrocarbons in kinetic head, and yields to them, especially to propylene, in DP temperature and blast sensitivity. Among the other fuels, acetylene holds a particular position due to its high blast sensitivity, the highest DP temperature, and its DP kinetic head very close to that of the other hydrocarbons. Taking into account DP chemical activity, acetylene is a promising solution for detonation spraying. Besides, it is helpful to mix with acetylene up to $50-70 \%$ of heavier hydrocarbons such as propylene, propane or butane to increase the kinetic head of the detonation products when spraying "heavy" materials such as WC-Co.

\section{Diagnostics of detonation spraying}

A flux of particles flying out of the barrel was registered by the CCD-camerabased diagnostic tool over a distance of $22 \mathrm{~mm}$. Images were captured with an exposure time of $10 \mu \mathrm{s}$ in different locations of the flux over a distance from 0 up to $900 \mathrm{~mm}$ from the barrel's end. To synchronize the image capturing with the explosion, a signal from the initiating electrical discharge was fed to the CCD-camera via a standard generator with a time-delay adjustable in the range 
of 0-100 ms. To control the synchronization, a photodiode was placed in opposite to the CCD-camera for registering the light emission from the gaspowder flux which was recorded together with the synchronizing signal by an oscilloscope [7]. The barrel filling with the explosion mixture (explosion charge) was varied in the range of $25-80 \%$ of the total barrel volume.

Spherical-shaped Ti $\left(4.5 \mathrm{~g} / \mathrm{cm}^{3}\right.$ density), SS $316 \mathrm{~L}\left(8 \mathrm{~g} / \mathrm{cm}^{3}\right)$ and WC-Co $\left(88 / 12 \mathrm{wt} \%, 14.3 \mathrm{~g} / \mathrm{cm}^{3}\right)$ particles were used in the experiments. The powders were sieved into narrow fractions: $<20,20-40$ and $40-50 \mu \mathrm{m}$.

Figure 1 presents experimental results obtained by analysing the track length of the Ti, SS and WC-Co 40-50 $\mu \mathrm{m}$ particles photographed at the outlet of the gun barrel. Comparison of the theoretical and experimental results for WC-Co particles presented in Fig. 1 shows that the experimental value of the velocity, indicated by triangles, does not go beyond the boundaries predicted by the model (curves 1 and 2). The difference between the theoretical and experimental results for Ti does not extend beyond the statistical dispersion of the particle size.

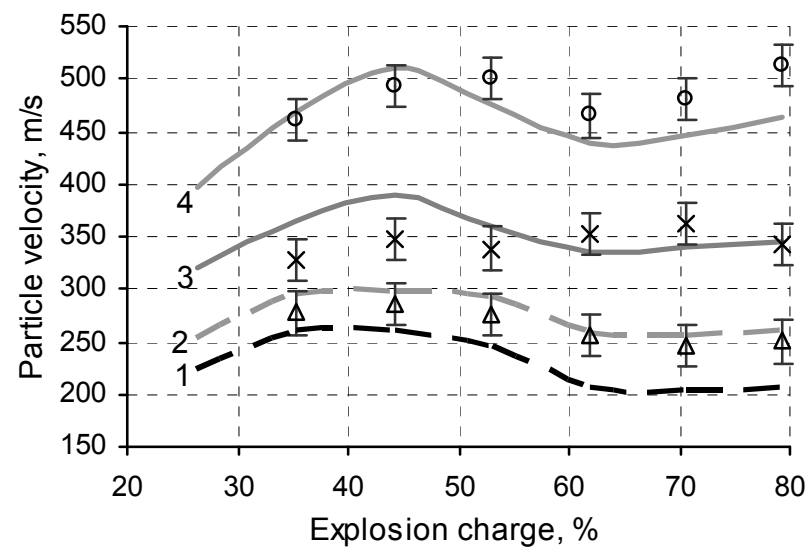

Figure 1: Particle velocity versus explosion charge. comparison of calculation (curves: 1 - WC-Co, mean particle size, $50 \mu \mathrm{m}$; 2 -WC-Co, $40 \mu \mathrm{m} ; 3$ - SS, $45 \mu \mathrm{m} ; 4-\mathrm{Ti}, 45 \mu \mathrm{m})$ and experimental (triangles - WC-Co, crosses - SS, circles - Ti) results.

Non-monotonous dependence of the particle velocity on the explosion charge registered at the barrel outlet is explained by the qualitative difference in particle acceleration when the boundary of the explosion charge reaches the zone of powder injection into the barrel that corresponds to $50 \%$ of the barrel filling by the explosion charge. For larger explosion charges, the deceleration in the rarefaction wave starts to play a significant role in the gas dynamics of the detonation products. The rarefaction wave penetrates the barrel after the exit of the detonation front which passes ahead of the more inertial particles.

The results of the series of experiments to analyze the external ballistics, i.e. particle-in-flight parameters outside the barrel, are presented in Fig. 2. 


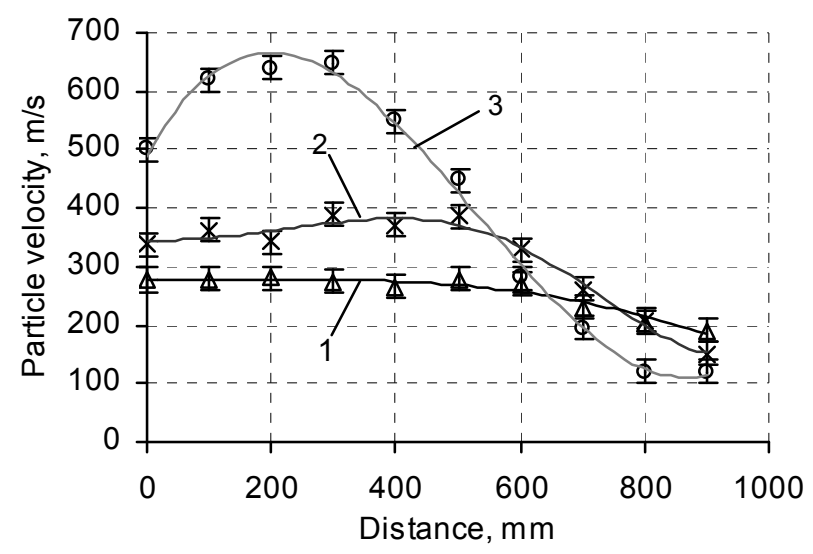

Figure 2: Particle velocities versus distance run outside the barrel. experimental results: $1-\mathrm{WC}-\mathrm{Co} ; 2-\mathrm{SS} ; 3-\mathrm{Ti}$.

The relatively "heavy" WC-Co particles practically keep constant velocity at a distance of $500 \mathrm{~mm}$ from the barrel outlet, and only beyond this distance they start slowly losing their velocity. On the contrary, SS particles are noticeably accelerated reaching their maximum velocity at a distance of about $400 \mathrm{~mm}$, and then abruptly start decelerating. As to the "light" $\mathrm{Ti}$ particles, they are accelerated till a distance of $200 \mathrm{~mm}$ run outside the barrel increasing their velocity by almost $30 \%$, and then a sharp deceleration of the particles occurs.
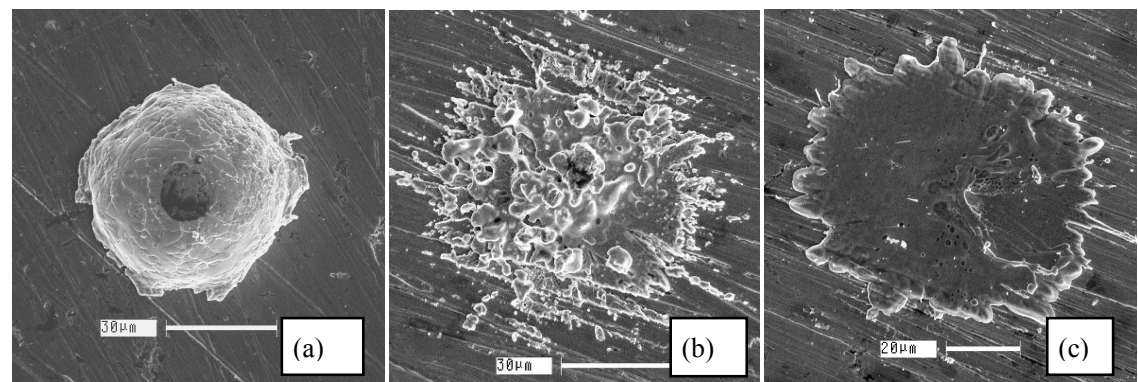

Figure 3: Splat morphology of $\mathrm{Ni}$ particles at different $V \& T$ collision conditions: Calculated $(V \& T)$ values: (a) $V \approx 360 \mathrm{~m} / \mathrm{sec}$, $T \approx 1450 \mathrm{~K}$; (b) $V \approx 420 \mathrm{~m} / \mathrm{sec}, T \approx 1700 \mathrm{~K}$; (c) $V \approx 460 \mathrm{~m} / \mathrm{sec}$, $T \approx 2200 \mathrm{~K}$.

\section{Formation of splats}

It is much more difficult to determine the temperature of the sprayed particles than to measure their velocity. But there is a possibility to apply a specific "reference point", i.e. solid-liquid phase transition that is realized in spraying 
process. This reference point can be found by observing the splats. Such kind of technique is described in [8].

Different V\&T conditions of the particle/substrate collision result in different modes of the particle deformation (Fig. 4). Splats resulting from the collision of hot but non-melted particles are cupola-shaped (Fig. 4a). This corresponds to the solid-state mechanism of the particle deformation. Collision of a liquid particle gives rise to a hydrodynamic flow, sometimes even with the jet formation, and the resulting splat has a flat pancake-like shape. Transition of a metal particle from the solid-state mode of deformation to the hydrodynamic one takes place at a temperature close to the melting point. For the composite materials whose components have significantly different melting points, e. g. WC-Co hard alloys, the transition temperature is higher than the melting point of the low-melt component (cobalt) [9].

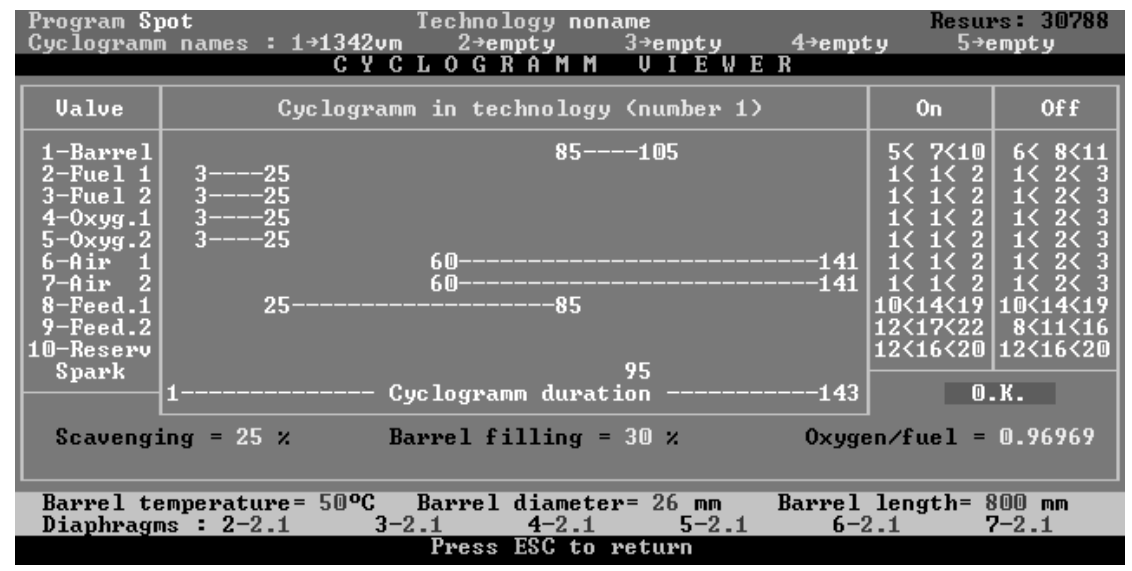

Figure 4: Software interface of CCDS2000 controller. Each shot is controlled by up to 10 independent parameters.

Experiments show that not only melted or partially melted particles can form a strong bonding with the substrate, but non-melted hot ductile particles as well. This depends on both particle and substrate composition and properties. If a particle is too cold and has low velocity, it erodes the substrate with no splat formation, similar to what happens in Cold Spray.

If the particle temperature exceeds much the material melting point, then a high-speed hydrodynamic flow occurs, the particle is splashed into drops and jets so that a considerable part of material is lost, and no effective coating formation is possible. So there is a certain V\&T range for the coating formation from a given powder on a given substrate, and it is possible to establish this range by examining splats. Another important parameter is the substrate surface roughness. DS practice shows that to provide reliably high adhesion of the coating, the substrate should be sand-blasted before spraying. 


\section{Applications of CCDS2000}

The exclusive advantage of CCDS2000 is comprehensive computer control over all process variables and operations. Special software creates an interactive interface presented in Fig. 4. It fully controls the explosion charge formation inside the barrel by varying the consumption of two fuels, oxidizer and inert gas, and permits to control the accurate powder feeding using two powder feeders. During spraying, the computer is checking all executors and safety blockings of the auxiliary equipment.

Two basic modifications of the CCDS2000 device were developed: the mobile and the stationary ones. The weight of the mobile device intended to be used with a robot is $18 \mathrm{~kg}$ (Fig. 5).

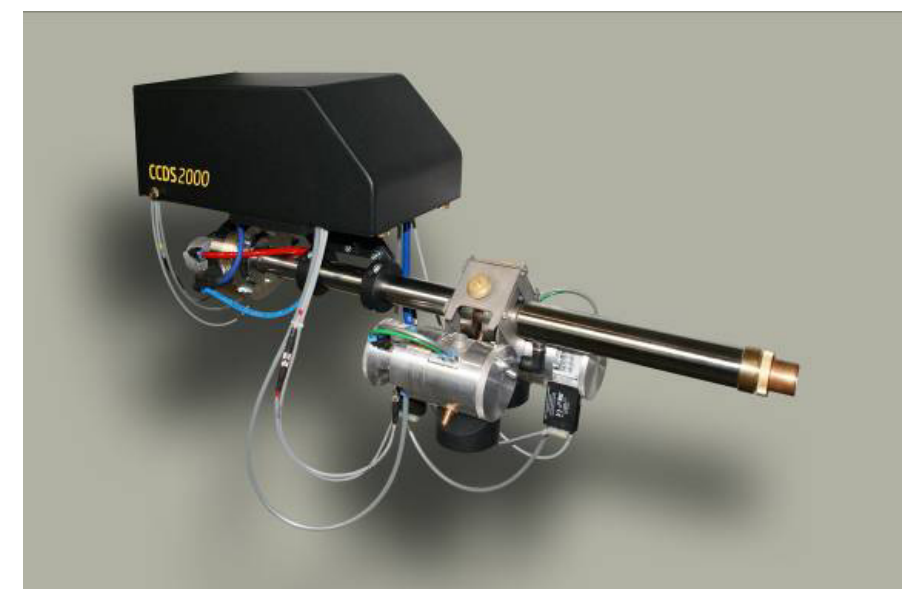

Figure 5: CCDS2000 equipment: robot compatible spraying unit.

CCDS2000 can be equipped with barrels of $10-50 \mathrm{~mm}$ diameter. It produces coatings with a thickness of 3-10 $\mu \mathrm{m} / \mathrm{shot}$ and can operate with a frequency up to $10 \mathrm{~Hz}$ (for $22 \mathrm{~mm}$ barrel diameter). Its powder feeding rate reaches $2000 \mathrm{~g} / \mathrm{h}$ for $22 \mathrm{~mm}$ barrel diameter and $10 \mathrm{~Hz}$ frequency, and $3000 \mathrm{~g} / \mathrm{h}$ for $30 \mathrm{~mm}$ barrel diameter and $8 \mathrm{~Hz}$ frequency, and the coefficient of powder utilization can be as high as $80 \%$ (for WC-Co powder). The optimal powder size distribution is in the range $15-45 \mu \mathrm{m}$. The standoff distance can vary in the range $100-500 \mathrm{~mm}$, and the substrate inclination - in the range $\pm 45^{\circ}$. The noise measurement at the barrel open end gave the value of $120 \mathrm{~dB}$ for $22 \mathrm{~mm}$ barrel diameter.

DS provides high-quality coatings and, among the other thermal spraying technologies, mainly HVOF can compete with DS in this respect. The great advantage of HVOF is its high productivity. CCDS2000 device does not show extremely high productivity, therefore, it is not suitable to cover surfaces of several square meters. However, it offers other advantages. DS is a discontinuous process allowing us to avoid substrate overheating during 
spraying. This enables to deposit coatings on materials with low melting points or low decomposition temperatures. A remarkable example is the metallization of plastics by DS [10]; coated samples are shown in Fig. 6.

CCDS technology enables to realize the so-called "delicate" modes of spraying and deposit such metals as aluminum, zinc and tin on PTFE, polyester, fiberglass, caprolan, etc. (Fig. 6(a)). Aluminum coating adhesion on plastics reaches $10 \mathrm{MPa}$. A number of metal or composite coatings can be deposited upon an aluminum under-layer (Fig. 6(b)).
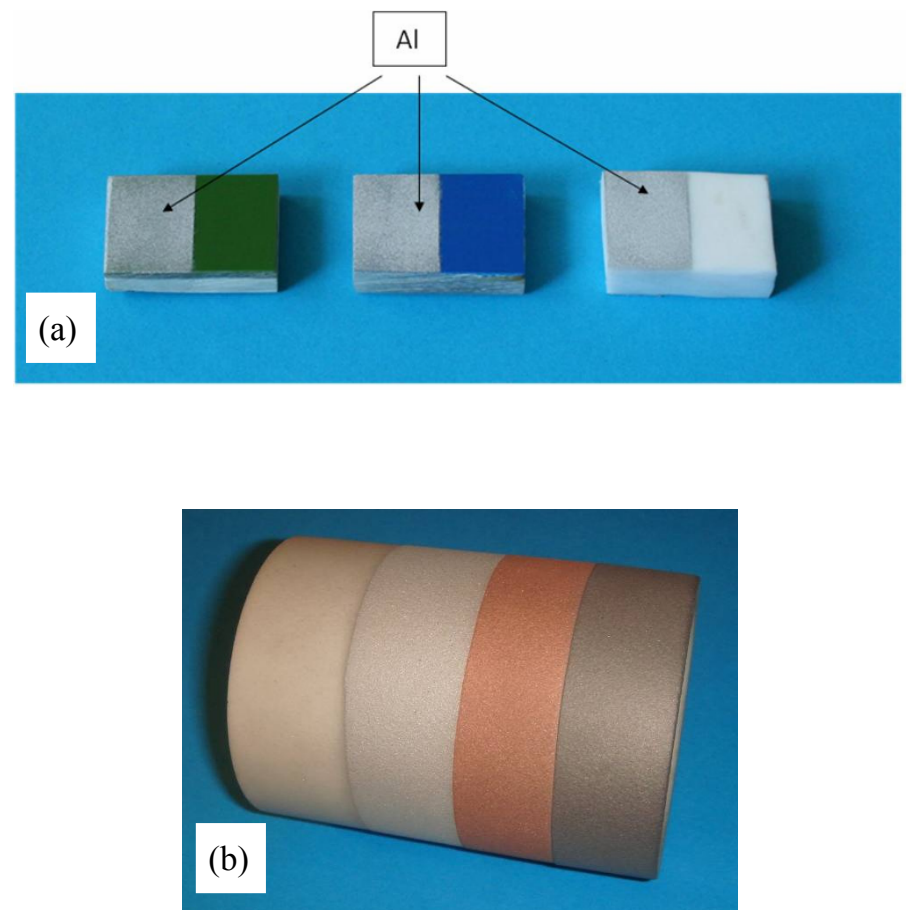

Figure 6: Plastics metallization: (a) - different plastics (polyester, fiberglass, Teflon) with aluminum coating, (b) - PTFE rod with a three-layer (Al, $\mathrm{Cu}, \mathrm{WC}-\mathrm{Co}$ ) coating with layers telescopically overlapped by each other.

CCDS technology is especially effective for deposition of coatings on small parts with complicated shape (Fig. 7). Computer controlled pulsed-mode of spraying together with the computer controlled moving of the part strongly reduce powder losses. 


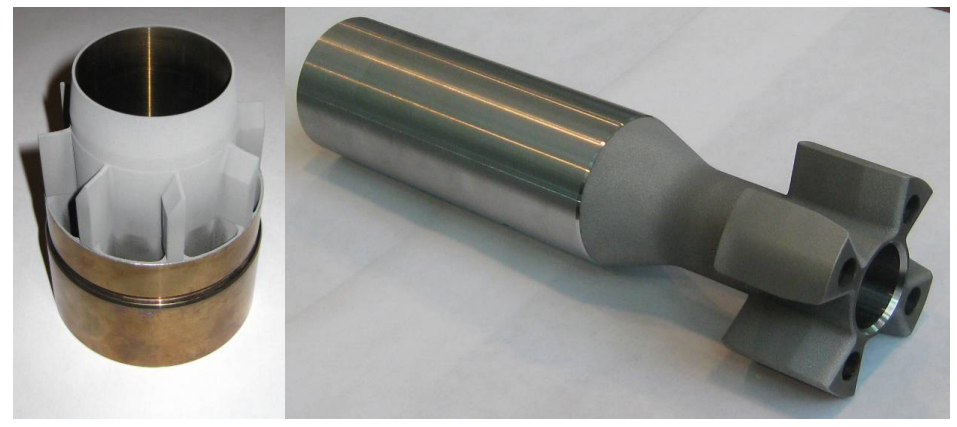

Figure 7: $\quad$ Part of oil-drill telemetric equipment hardened by WC-Co coating.

Thermal spray technologies are often used for the refurbishment of worn out mechanical parts. In this application, coatings made from self-fluxing alloys, cast iron, and some steels are usually utilised. CCDS technology is advantageous for repairing parts having complicated shape, and/or inner surfaces difficult to access as, for example, components of electro-centrifugal submersible pumps employed in oil-producing industry (working wheel and guide apparatus, Fig. 8).

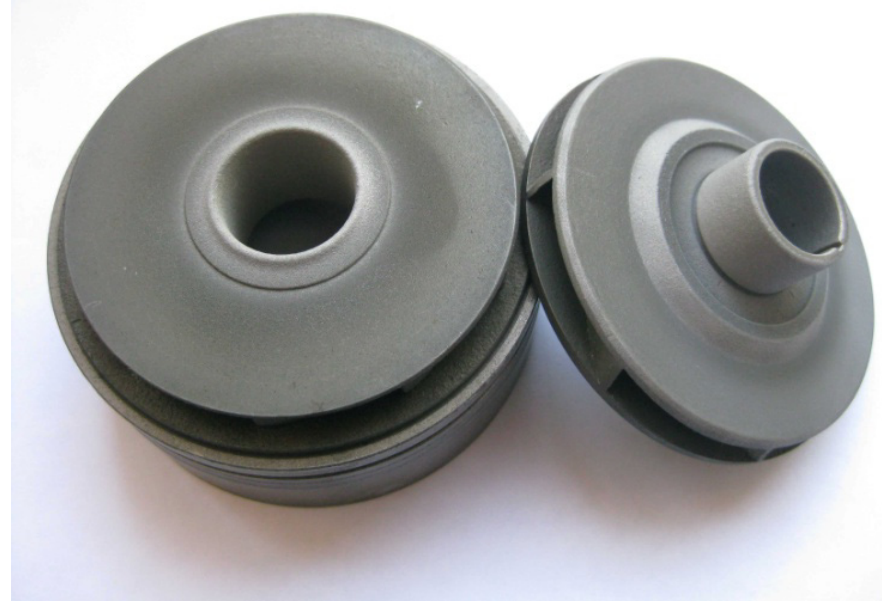

Figure 8: Oil pump parts restored by CCDS technology using SS powder.

It is expected that nanostructured WC-Co powders recently appeared on the market could provide better coating properties than the conventional ones. The performed experiments shown that detonation sprayed coatings from nanostructured powders (Mechanomade 301 and Mechanomade 308, MBN, Italy) have no particular advantages over the coatings from conventional alloys with the same WC and Co content [9]. However the synergetic effect was found 
indicating that coatings made from mixtures of nanostructured and conventional powders sometimes exhibit substantially improved tribological performance. To prevent decomposition of WC grains during spraying, it is advisable to use spraying conditions when particle overheating does not exceed the Co melting point by more than $30 \%$.

There is a demand in nuclear industry for high electric insulation inorganic coatings on components with complicated shape. This problem was solved with the help of CCDS technology by deposition of dense alumina coatings with high electric insulation (up to $5 \mathrm{kV}$ ) strength (Fig. 9).

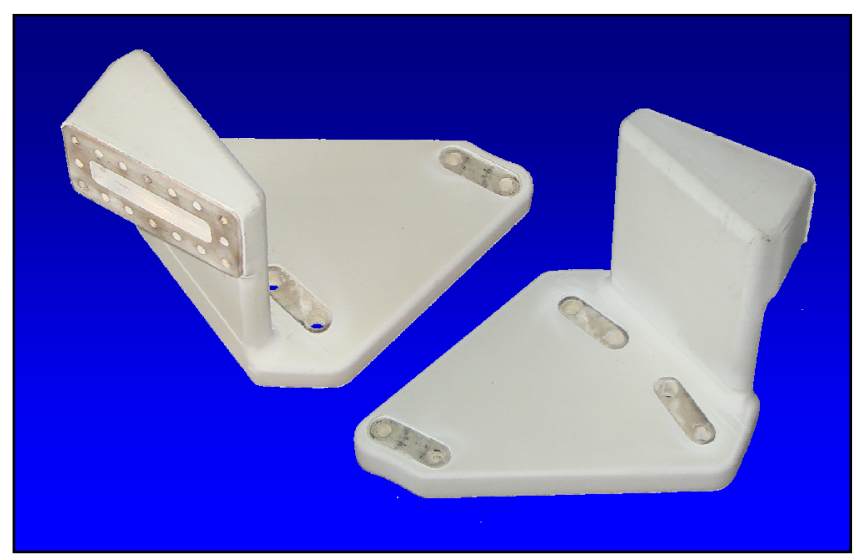

Figure 9: Copper parts of nuclear physics equipment with alumina insulating coating.

Adhesion of the coatings deposited by CCDS2000 on a steel substrate from WC-Co(88/12) powder produced by Praxair, Sulzer Metco, Woka, Stark, and Durum reaches $150-180 \mathrm{MPa}$, from most metals and alloys - 110-180 $\mathrm{MPa}$, and from ceramics, for example $\mathrm{Al}_{2} \mathrm{O}_{3}$ - only 50-80 MPa. An extremely high adhesion of 250-300 MPa can be achieved in spraying WC-Co (75/25 wt \%) by increasing the content of cobalt which is the main responsible for the quality of adhesion of the coating to the substrate. CCDS equipped with twin feeders allows to deposit WC-Co (75/25 wt \%) interphase layer and, thus, to achieve more than $200 \mathrm{MPa}$ adhesion for consecutively sprayed powders.

Computer control of multiple parameters adjustable for each shot together with numerical command of the twin powder feeder offer large possibilities for forming a variety of composites by providing the optimal spraying conditions for each of the two components (Fig. 10). Layered coating architecture can be realized such as metal-metal, metal-ceramics, ceramics-ceramics and cermets with metal interlayers, etc. In this regard, the coating architecture with layer-bylayer gradient seems to be promising to smooth a strong difference in physical and mechanical properties between the substrate and the coating [11]. 


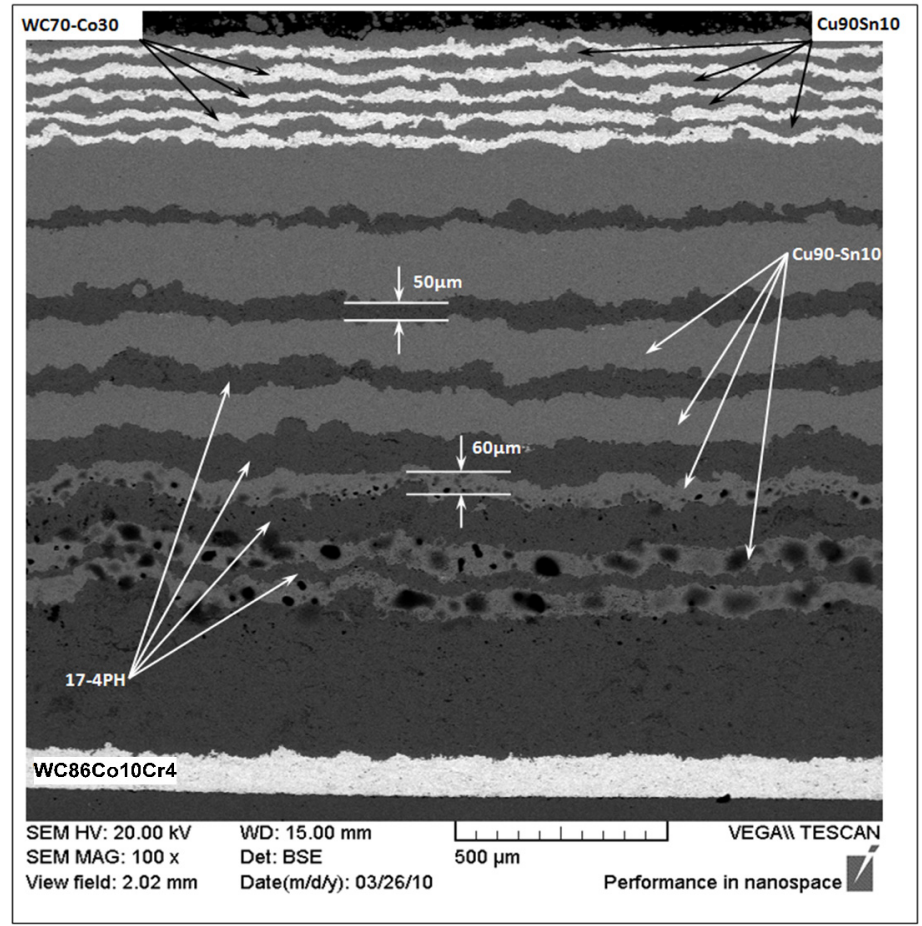

Figure 10: Multi-material model coating: WC-Co-Cr + SS (17-4PH) $+\mathrm{CuSn}+$ WC-Co (70/30 wt\%).

\section{Conclusion}

CCDS was used for the deposition of different powders: metals, special alloys, cermets (carbides of tungsten, chromium, titanium with $\mathrm{Co}$ or $\mathrm{Ni}$ binder) and ceramics. Non-metallic substrates, including ceramics and plastics, were used.

Measurements of the particle-in-flight velocity using optical diagnostics were performed, and the results are compared with numerical simulation: Particles sized between 10 and $50 \mu \mathrm{m}$ and having density from 4.5 up to $14.3 \mathrm{~g} / \mathrm{cm}^{3}$ are accelerated at the barrel outlet up to $250-750 \mathrm{~m} / \mathrm{sec}$. Experiments revealed that outside the barrel light particles may be accelerated by further $15-30 \%$.

Experiments with the splat formation are compared with calculations of the particle temperature at impact. It was shown that, in detonation spraying, particles with temperature $15-20 \%$ below the melting point are strongly fixed on a flat substrate, as in Cold Spraying. On the other hand, particle overheating by $30-50 \%$ above the melting point results in droplets sputtering and splats cracking. The same powder could be sprayed in a solid state or being strongly overheated above the melting point by variation of the quantity of the explosive gas mixture, which is computer controlled. Recent progress in detonation 
spraying shows that coatings with advanced performance can be applied in: aircraft and aerospace, machine-building and ship-building industries, equipment for oil/gas and chemical industries, machines for wood processing and paper production, equipment for food industries, components of electrical and electronic devices.

\section{References}

[1] Yu. Nikolaev, A. Vasiliev, V. Ulianitsky, Gas Detonation and its Application in Engineering and Technologies (Review), Combustion, Explosion, and Shock Waves, 2003, 39 (4), p 382-410.

[2] R. Poorman, H. Sargent, and H. Lamprey, Method and Apparatus Utilizing Detonation Waves for Spraying and other Purposes, U.S. Patent №2714563, 1955.

[3] J. Pelton, Flame Plating Using Detonation Reactants, U.S. Patent № $2972550,1958$.

[4] S. Bartenev, Yu. Fedko, A. Grigorov, Detonation Coatings in Machinery Building, Leningrad, Mashinostroenie, Leningrad section, 1982 (in Russian).

[5] T. Gavrilenko, Yu. Nikolaev, V. Ulianitsky, D-Gun «Ob» Detonation Spraying, Thermal Spraying: Current Status and Future Trends, Akira Ohmori, Ed., May 22-26, 1995 (Kobe, Japan), High Temperature Society of Japan, 1995, vol. 1, p 425-429.

[6] T. Gavrilenko and Yu. Nikolaev, Calculation of Detonation Gas Spraying, Combustion, Explosion, and Shock Waves, 2007, 43 (6), p 724-731.

[7] I. Smurov, D. Pervushin, Yu. Chivel, B. Laget, V. Ulianitsky and S. Zlobin, Measurements of particles parameters at detonation spraying, Proceedings of the International Thermal Spray Conference, ITSC, Singapore, 2010.

[8] S. Zlobin, V. Ulianitsky, A. Shtertser, I. Smurov, High-Velocity Collision of Hot Particles with Solid Substrate, under Detonation Spraying: Detonation Splats, Thermal Spray: Expanding Thermal Spray Performance to New Markets and Applications, B. Marple, M. Hyland, Y. Lau, C. Li, R. Lima, G. Montavon, editors, May 4-7, 2009 (Las Vegas, Nevada, USA), ASM International, p 714-717.

[9] V. Ulianitsky, A. Shtertser, S. Zlobin, I. Smurov, Comparative Analysis of Tribological Properties of Cermet Detonation Coatings, Thermal Spray: Thermal Spray Crossing Borders, E. Lugscheider, Ed., June 2-4, 2008 (Maastricht, the Netherlands), DVS -Verlag GmbH, Düsseldorf, 2008, p. 125-131.

[10] V. Ulianitsky, A. Shtertser, S. Zlobin, I. Smurov, Metallization of Plastics by Detonation Spraying, Thermal Spray: Thermal Spray Crossing Borders, E. Lugscheider, Ed., June 2-4, 2008 (Maastricht, the Netherlands), DVS Verlag GmbH, Düsseldorf, 2008, p. 987-989.

[11] A. Sova, D. Pervushin, I. Smurov. Development of multimaterial coatings by cold spray and gas detonation spraying. Surface \& Coatings Technology, vol. 205, 2010, pp. 1108-1114. 